Published in E. Goody (Ed), 1995 Social intelligence and interaction, p. 153-174. Cambridge University Press.

\author{
PENELOPE BROWN
}

\title{
7 Politeness strategies and the attribution of intentions: the case of Tzeltal irony
}

In this chapter I want to take up the idea that human thinking is systematically biased in the direction of interactive thinking (E. Goody's anticipatory interactive planning, or AIP), that humans are peculiarly good at, and inordinately prone to, attributing intentions and goals to one another (as well as to non-humans), and that they routinely orient to presumptions about each other's intentions in what they say and do. I want to explore the implications of that idea for an understanding of politeness in interaction. I shall take as a starting point the Brown and Levinson model of politeness, which assumes interactive thinking, a notion implicit in the formulation of politeness as strategic orientation to face.

Brown and Levinson $(1978,1987)$ have proposed a model of politeness wherein human actors are endowed with two essential attributes: face and rationality. We claim that face consists of two specific kinds of wants: positive face (i.e., the desire to be approved of, admired, liked, validated), and negative face (the desire to be unimpeded in one's actions). The second ingredient in our model is rationality, the ability to reason from communicative goals to linguistic means that would achieve those goals. From these two assumptions - face and rationality - and the assumption that speakers universally mutually know that all speakers have these attributes, we developed a model of how speakers construct polite utterances in different contexts on the basis of assessments of three social factors: the relative power $(P)$ of speaker and addressee, their social distance (D), and the intrinsic ranking ( $R$ ) of the face-threateningness of an imposition. $P, D$ and $R$ are seen as abstract social dimensions indexing kinds of social relationship ( $P$ and $D$ ) and cultural values and definitions of impositions or threats to face (R). The claim, then is this: however culturally variable definitions of kinds of social relationship and kinds of face threat might be, underlying them are pan-cultural social dimensions (relative power, social distance, ranking of face-threateningness) which universally go into the reckoning - and the interpretation - of strategic language choice, and hence we derive the cross-cultural similarities in 
choice of linguistic realizations of politeness strategies that empirically seem to be in evidence. We then went on further, to claim that this model of politeness universals could be applied in particular cultural circumstances as an ethnographic tool for analysing the quality of social relationships.

In this Brown and Levinson framework, then, sociolinguistic variation (different kinds of language use in different situations) is portrayed as rationally tied - via demonstrable means-ends reasoning links - to the kinds of things people are trying to do when they speak, and cross-cultural parallels are viewed as attributable to the existence of similar rational processes underlying human interaction.

This model (and the Gricean model of communication which underlies it) makes very strong assumptions about humans' abilities to reason reflexively about each others' desires and intentions. To operate according to the model, speakers have to be able to modify the expression of their communicative intentions so as to take account of what they see as their interlocutor's views of what they might be taken to be wanting to communicate, including what impositions to face might be on the table, as well as his or her assessments of the speaker's and hearer's relative power and social distance. Correspondingly, interlocutors must be able to read such modifications as evidence that the speaker is inferring particular things about their own views, desires, and intentions in this context. An enormous amount of reasoning, therefore, would have to go into the construction of any utterance, and one might well be forgiven for thinking that human communication along these lines is simply impossible.

One way of finessing some of this reasoning might be by using conventionalized politeness strategies, where politeness meaning is conventionally attached to certain linguistic forms: for example, formulaic expressions like 'please' and 'thank you', or conventionally indirect speech acts like 'Could you pass the salt?' where the polite hesitancy of 'Could you?' cannot be read literally and therefore automatically conveys polite restraint. This is, I think, how the 'person on the street' tends to think about politeness, as inhering in particular linguistic forms.

And indeed, many interpreters of the Brown and Levinson model have fallen into the trap of thinking of linguistic realizations of politeness strategies as necessarily conveying the particular sort of politeness we associate them with, as if all politeness realizations were conventionalized, as if any instance of the use of an in-group address form or an exaggerated expression of interest were necessarily positively polite, for example.

What I want to demonstrate here is that not only is this clearly untrue no necessary politeness associations attach to any linguistic form in situated discourse, or rather, whatever associations attach to a form out of context may be undone in its situated use. But further, conventionaliza- 
tion does not provide the easy solution to intention-attribution that it first appears to. Conventionalized politeness strategies still have to be interpreted in relation to presumed speaker intentions in context.

One of the ways this lesson was drummed home to me was in my confrontation with a conventionalized form of expression in Tzeltal, a Mayan language spoken in the peasant Indian community of Tenejapa, in southern Mexico, where my ethnographic fieldwork has been concentrated. ${ }^{1}$ I have called the phenomenon 'Tzeltal irony', as it is basically a matter of uttering propositions which are in the context taken to convey the 'opposite' or the 'inverse' of what they literally appear to mean. Ironic assertions in Tzeltal most frequently appear phrased as hedged negative assertions usually preceded with $y u$ ', 'because', such that uttering a proposition (P) in the form $y u^{\prime}$ ' $m a P-u k$ ('because it is not, possibly, the case that $P$ ') conveys the emphatic assertion that ' $P$ ' is the case. ${ }^{2}$ This form of expression is elaborated in Tzeltal to an extent that far exceeds the use of ironic expressions in, say, English or the other languages which have been used to elucidate the nature of irony. There is an enormous philosophical and linguistic literature on this topic; I do not address it here but rather try to disentangle the Tzeltal phenomenon as a thing sui generis. ${ }^{3}$

In the context of this book, there are two main reasons for taking an interest in this phenomenon:

First, because of the cognitive processes involved: the production and understanding of ironic utterances seems to require an enormous depth of reflexive reasoning, and a reliance on the firmness of mutual understanding between interlocutors, who must assume that they share mutual knowledge about what each other thinks each other thinks could/must be true. Just how is this mental acrobatics achieved?

Secondly, because of the ethnographic puzzle: in Tzeltal, ironies are used to construct social relationships of a particular kind. How and why is this done through conventionalized irony?

To elaborate: ironic expressions, and their close relative rhetorical questions, are a very pervasive and salient feature of Tzeltal speech in interaction. They are an important ingredient in the expression of positive politeness in this society, used for stressing agreement, sympathy, understanding and commiseration; they are therefore especially in evidence in women's speech. Both syntactically and functionally, Tzeltal ironies are very closely related to rhetorical questions, understatement, and negative assertions (presuming a positive response) - an intriguing class of utterance types that gives a distinctive flavour to Tzeltal interaction, all of which involve conveying the 'opposite' of the proposition expressed plus an attitude to it, and carrying the interactional pressure for the addressee to respond to this attitude.

They are therefore quintessential examples of inter-subjective 
perspective-setting and -taking' (Luckmann, Chapter 8, this volume), and merit our attention to the complex reasoning processes involved in the achievement of this.

In passing, I might add that Tzeltal ironic expressions lend themselves to a Sperber and Wilson (1982) type of treatment, which views irony (and more loosely ironical utterance types) as echoic mention. All these sorts of 'figures of speech' are seen as essentially 'echoing' or more loosely evoking a proposition which is placed in the context to be laughed at, scorned, or whatever, in order for an attitude to be conveyed towards it. Ironic utterances are like things in quotes, so for example if someone says 'Nice day, eh', in a context of a walk in the pouring rain and sleet, the false description evokes the image of the accurate description ('Rotten day, eh') as well as an image of who might have, or actually did, utter the hope/ prediction/expectation that it would be a nice day, this person (or image) then being the imagined 'victim' or target of the ironic utterance. The Sperber and Wilson account doesn't claim that all this is the 'meaning' of the utterance, but rather a set of reasoning processes to get from what's said to what's intended to be conveyed.

In Tenejapa, ironies, rhetorical questions and understatements are an important ingredient in all sorts of evaluative discourse - gossip, complaint/commiseration sequences, verbal play (joking, mockery, banter) as well as in other breaches of the 'quality maxim': verbal deceit, social lies (e.g., the token refusal of offers, pseudo agreement, and denying knowledge of answers to nosy questions). They add up to a peculiarly Tenejapan (and especially Tenejapan women's) way of speaking, conventionalized and elaborated in many domains, and tied to other aspects of Tenejapan social life - to non-committalness, fatalism, values about privacy, vulnerability to gossip, avoidance of open conflict, for example. ${ }^{4}$

Let's look, then, at the culturally standardized use of ironic expressions among Tzeltal-speaking Tenejapans.

\section{Tzeltal ironic expression - some politeness strategies in use}

An understanding of ironic expression in Tzeltal requires two things: (1) an analytical approach to irony within a universal framework - an analysis of the kinds of jobs irony can do in conversation, by virtue of its rationally based construction oriented to Grice's 'maxim of quality'. In Brown and Levinson (1987) we analyse irony as a politeness strategy which is an off record strategy in origin, but in context can be positively polite. ${ }^{5}$ But ironic expression in Tzeltal is conventionalized off record, for very often no non-ironic reading is entertainable in the context, and therefore we also need (2) an understanding of normatively stabilized usages in Tzeltal, and of how such normative stabilizing affects what ironically phrased utterances can be taken to mean in different contexts. 
I choose to develop such a complex example here because with it I can show how a given type of linguistic form can have multiple situated meanings and therefore multiple politeness (and impoliteness) functions; an ironically expressed utterance can, in context, convey any of the three types of politeness superstrategies: it can be (1) genuinely off record, ambiguous in the context as to whether an ironic reading is intended; it can be (2) negatively polite by virtue of being conventionally indirect, and (3) perhaps most characteristically, it can be positively polite, emphasizing common ground; it can also convey impoliteness. But, though the interpretation changes with the context, the underlying strategic orientation to face concerns shows through across contexts. So in this society, in which $I$ have described the women as prone to emphasizing positively polite expression amongst themselves (Brown 1979, 1980), I want to show what happens to women's affiliative speech style, and specifically what happens to the interpretation of potentially ironic expressions, when hostility, anger or mere suspicion characterizes their interaction.

First I'll briefly characterize the Tzeltal ironic formulations, and show how they work in ordinary cooperative speech. Then I'll illustrate their use in a Tenejapan courtroom confrontation, where they become sarcastic agreement used to emphasize disagreement. And finally I'll illustrate the intricacies of ironic/rhetorical expressions in a more ambiguous case, where ironic expression hovers between affiliative and dissociative functions during the conversation.

\section{Conventionalized Tzeltal ironic/rhetorical expression}

There are three basic ways of constructing ironic/rhetorical utterances in Tzeltal, as summarized by the following formulae: ( $P$ represents the proposition as expressed in the surface structure; $\rightarrow$ is to be read as 'conversationally implicates', that is 'in the context conveys'):

Type 1: a hedged or questioned proposition, optionally introduced by 'because' (yu'un), optionally with the subjunctive $-u k$, and optionally with dubitative or emphatic particles which may force an ironic reading:

$\left(y u^{\prime} u n\right)+\mathrm{Q} /$ hedge $+\mathrm{P}+(-u k)+($ emphatic particle $(\mathrm{s})) \rightarrow$ 'not $\mathrm{P}$ '

Type 2: a negative proposition, hedged or questioned, again optionally with $-u k$ and dubitative or emphatic particles:

$\left(y u^{\prime} u n\right)+\mathrm{NEG}+\mathrm{P}+\mathrm{Q} /$ hedge $+(-u k)($ emphatic-particle $(\mathrm{s})) \rightarrow$ ' $\mathrm{P}$ '

Type 3: a WH-questioned proposition (who/why/when/where/what/ how), again optionally hedged and/or emphasized:

WH-Q $+\mathrm{P}+($ hedge $)+($ emphatic particle $(\mathrm{s})) \rightarrow$ No one, no where, no way, for no reason, $\mathrm{P}^{\prime}$ 
My reason for treating ironies and rhetorical questions as essentially the same is that the basic mechanism of construction is the same for both, the only difference being that in ironies, the proposition (phrased as the 'opposite' of what the speaker intends to convey) is hedged with dubitative particles, while in rhetorical questions it is hedged with a question particle. In both cases emphatic particles and/or prosodics may (optionally) disambiguate the intended meaning.

\section{Examples: the basic phenomenon 6}

Example 1. Context: story about a girlfriend who hangs out with several different men; $S$ is here emphasizing her own attitude to the risks of associating with her.

yu'un niwan ya $j-k^{\prime}$ an ya $j$-ta mul ya $k-a^{\prime} y$ because perhaps ICP I-want ICP I-find crime ICP I-know/feel Because perhaps I want to find trouble, I know. $((\rightarrow$ 'Of course I don't want to get into trouble!'))

Example 2. Context: talk about a man who owes $S$ money and won't pay it.

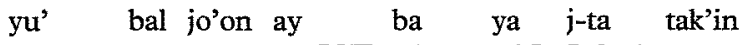

because $Q$ I EXIST where ICP I-find money

Because is there anywhere I'll find money?

$((\rightarrow$ 'Of course not!' (soliciting H's sympathy.)))

Example 3. Context: $\mathrm{S}$ is commiserating about H's problems with her chickens, and offering sympathy.

ma wan tey-uk nax ay ek

NEG perhaps there-SUBJ just EXIST too

It might perhaps not be the case that (the weasels) just are there too.

( $\rightarrow$ 'They certainly are there!'))

Example 4. Context: following a humiliating request when a man has asked his younger sister to mend his son's schoolbook, thereby revealing a breach with his wife whose job it is; his mother sympathizes with his need.

$\begin{array}{llll}\text { bi_yu'un nix ay } & x-a^{\prime}-n a^{\prime} & \text { s-tz'isel } & \text { ek a } \\ \text { why just EXIST } & \text { ASP-you-know } & \text { its-sewing } & \text { too }\end{array}$

Just why would you know how to sew it?

$((\rightarrow$ 'Of course you wouldn't'?))

It is important to note that utterances constructed according to these formulae are not necessarily ironic (though particle combinations especially hedge + emphatic particle-may force an ironic reading, and so may prosodics, facial expressions, etc.). But they are contextually disambiguated, via the assumption of mutual knowledge of each other's beliefs, 
attitudes, values, and likely events. Further, when ironic they do not necessarily convey a barbed negative evaluation of some specific target; the proposition that is held up to scrutiny is not necessarily attributable to any particular person.

\section{Sequencing in conversation}

The archetypal use for Tzeltal irony and rhetorical questions is as positively polite emphasizing of held-in-common opinions, values, and understandings. This is displayed in the ways in which they are responded to in interaction. Sometimes the response continues in the ironic vein, sometimes it 'translates' the irony with a straight response. Example 5. Context: story about husbands working on coffee finca.
A: ... mak ma wan xch' ajubotik ta stamel in ch'i
(coffee, that has fallen to the ground) then! ( $\rightarrow$ sympathetic
understanding: 'Of course, it's tiring!'))
B: mak bi yu'uni ma xch'ajub
Perhaps why don't (we) get tired. (( $\rightarrow$ 'We sure do!'))
A: yak mak
Yes, perhaps. ((Agrees with implicature.))

... perhaps it's not possibly that we get tired from bending over to pick

Example 6. Context: grown daughter just arrived back from several days' visit in town has been telling her mother what happened there. Her mother (A) reacts sympathetically to her tale of trials.
A: yu' ma sakubenuk a jul ch'i
Because not sort of pale, you arrived, to be sure! ( $\rightarrow$ 'Gosh have you ever come home pale!' i.e., 'Poor you, what problems you've had!'))
B: a sakub
Oh (yes), pale. ((Straight reply, agrees with the implicature.))
A: saktuntun nanix a kil
Really pale, I see. ((Agrees with agreement.))
B: ya'ben julel.
Pale and thin (I've) come home. ((Agrees with agreement.))

Equally, ironies may be used to elicit sympathy:

Example 7. Context: household visit; smalltalk about crops.

P: jm. bi yilel? lek bal a laj ala ch'i yilel?

Oh. How does it look? Is it (your chili) growing well? ((Straight question.))

M: banti lek ya xch'i. mak yu' ma ja'uk kola' a ya'y xan, jich nix a taot xan ja'al ini.

Where does it grow well. ( $(\rightarrow$ 'Nowhere; it's not growing well'. $))$ Perhaps because it's not the case that it's rotting again, thus it has just encountered this rain again. ( $(\rightarrow$ 'It is rotting, from the rain.'))

Example 7 also illustrates the fact that ironic utterances are not solely used to engender repeat cycles of agreement on mutually known facts; they are 
often used to inform on matters about which the addressee has no personal knowledge. However, in these cases the addressee has the option to respond without agreement - indeed, with doubt or outright denial of the conveyed proposition, thus conveying that the prior speaker's presumption of shared knowledge/attitudes was in this case unwarranted.

But when ironies are used to proffer an emphatic opinion, the response may continue in the same mode, so that the whole interchange is carried on in a non-literal mode (whilst appearing to be revelling in their agreement that ' $\mathrm{P}$ ', they are really assuring each other on their agreement that 'not-P'). For example, in this exchange:

Example 8. Context: girls gossiping about a newly married friend.

A: ya wan xjalaj xkal

She perhaps will stay a long while, I say. ( $\rightarrow$ ‘'Of course she won't stay long with her new husband.'))

B: yu'wan ma ya sta o'tanil.

Because perhaps she won't get tired of him. $\left(\left(\rightarrow^{\circ} \mathrm{O}\right.\right.$ f course she will tire of him!'))

Here, by rephrasing A's ironic comment rather than merely repeating it, $B$ demonstrates her understanding of A's ironic intention, and provides even stronger accord and agreement. This can presumably only be pulled off if they can with reason presume that they do in fact share similar presumptions about the likelihood of (in this case) the friend sticking to her new husband. (If in fact they didn't share the same views, the thing would proceed in a different direction, as each pulled the inferential structure in the direction of her own (incompatible) set of beliefs.) Similarly, in the following joking exchange, we find ironic irony, again requiring shared attitudes (in this case, to the undesirability of marrying a Ladinoized Indian and the probability of marrying a real Tenejapan) as a prerequisite to its successful achievement:

Example 9. Joking exchange in context of gossip session about a woman who has been pursuing a married man; they've just agreed that it's better to go after unmarried men.

ANT: ... ja' ya jk'an xbaon ek in ta lumi. ((laughing))

It's that I want to go to town, too. (Indirect reference to one of her unwanted suitors, who wears Ladino clothes, speaks Spanish and lives in town.)

( $\left(\rightarrow\right.$ 'T want to go to town to see this lovely boyfriend, ha ha. $\left.\left.{ }^{\prime}\right)\right)$

$\mathrm{x}$ ((laughing)) solel ta lum ya'k'an ban.

Wow, to town you want to go!

ANT: ja' ya jk'an ba jmulan ek in lumi, ja' eki sawuli.

It's that I want to go enjoy town, it's this Sawul-fellow (who tempts me there).

$x$ : yu'un nix wan ma ja'uk leke, joyob kaxlan ye $t z$ 'in.

Because perhaps it wouldn't just be good, he's completely Ladinoized.

( $(\rightarrow$ 'That would be great, since he's Ladinoized.')) 
ANT: joyob yetz'in. 5

Completely, to be sure.

x: yu' wan indijena to yich'at yael ya'wa'y a tz'in ch'i.

Because perhaps an Indian will marry you you know then.

$((\rightarrow$ first-level implicature: 'Of course not; you'll marry a Ladino.'))

$((\rightarrow$ second-level implicature: joking; 'Of course we really know you'll marry an Indian.'))

ANT: eh kaxlan ya xk'oon ta lum ya'wa'y tz'in ch'i.

$\mathrm{Oh}$, as a Ladino I'll arrive in town you know then.

$((\rightarrow$ agreement with ironic reading; 'Not as an Indian's wife but as a

Ladino's wife will I appear in town.'))

x: k'unk'un ala bestido ya'wich'ix ala bechel ek a.

Gradually you'll wear Ladino clothes yourself too! 
personified voice of public opinion, or of malicious gossip - whoever might be likely to be making these patently false, and patently contranormal female-role-expectations claims about the subject of the ironic assertions. Structurally what seems to be going on is that the girls play off their own (real) attitudes and fears against a personified voice of public opinion that is bad-mouthing them. This bad-mouthing can be straight, or it can be ironic itself, as we saw in example 9 where the girls were teasing one girl about marrying a Ladino. In that case, the apprehension about public opinion is that it will suggest that they, true Indian girls, will marry Ladinos and 'go over to the enemy' as it were. So representing that voice in an ironic manner, they say 'Oh yes, sure you're going to marry an Indian' conveying ironically the voice of public opinion's conviction 'I bet you're going to marry a Ladino.' It is against this puppet voice of public opinion that the jokes about sex role identity take their force. ${ }^{8}$

The same sort of process, the setting up of a 'voice of malicious gossip' against which communicative intent is to be read, seems to be involved in other characteristic forms of Tenejapan expression. It appears in Tenejapans' self-mockery, as when they say, in effect: 'I'm stupid, lazy, useless, my clothes are full of holes, ...' This can be friendly joking; it can however take a more pointed turn, for example in teasing one's close household members about non-love and non-care (scenario: 'You (I) are poor and homeless, no parents, no food, will die of the cold and starvation, will be thrown to the dogs to eat, etc. etc.'). Such joking can carry heavy, non-affiliative implications, and the same format can be used as an indirect expression of anger.

Which leads us to our next set of examples: what happens to women's affiliative positively polite style in situations of open conflict?

\section{Angry irony}

Tenejapan women, of course, don't invariably engage in positively polite affiliative interactions. Conflict, overt anger and scolding, do occur, however normatively disapproved of, and it is instructive to look at ironic expressions in these sorts of contexts.

But first a few words about conflict in Tenejapa. Women in daily interaction tend to suppress conflict; it is veiled, even in private, and between non-intimate adult women openly angry confrontation rarely occurs. When one is angry, interaction with the provoker of one's anger is simply avoided, and gossip, mockery and backbiting against the object of one's anger are expressed to sympathetic intimates. Anger between women who are intimates is normally expressed through controlled 'leakage': silence, non-responsiveness or terse replies, and kinesic distancing, which in contrast with normal relaxed behaviour may suggest anger. 
There are however two types of contexts in which open conflict is not only tolerated but expected from women. One is in courtship, which traditionally is coloured by the girl's (apparent) outrage at being approached; the other is in court cases or more informal grievance hearings. In both of these contexts, ironic/rhetorical expressions abound. These, in such contexts of hostility or conflict, can be used to emphasize the attitude of hostility, as in this (reported) example of a girl's reaction to her unwanted suitor:

Example 10.

ANT: ej yu' bal xbiket mach'a ya ya'yat mene' xkut.

'Oh, is it that the one who hears you is happy', I said.

$\left(\left(\rightarrow{ }^{5} \mathrm{No}\right.\right.$, you sure don't make anyone happy, you creep.'))

In the next example, taken from a Tenejapan court case which was filmed and tape-recorded in 1980 by Stephen Levinson and myself, two women angrily confront one another in a public forum.

Example 11. Context: $P$ (plaintiff) is claiming that $D$ (defendent) owes her various debts; $D$ is denigrating the value of the goods she allegedly owes $P$ for. Immediately preceding context: $P$ has been listing her claims; $\mathrm{J}$ (judge) has just said 'wait a minute' and begun to write them down, one by one. (Underlined line numbers indicate ironic/rhetorical utterances) ${ }^{9}$

$\mathrm{J}$ : te: um (1.5) tzekel tz'i

(for the) skirt, then?

P: jm (.) ox-chejp tz'in tzekele (1.5) cha'chejp chujkilal

$\mathrm{Hm}$, three hundred then for the skirt, two hundred for the belt. ((Making a claim for what $D$ owes her for these items.))

D: bi yu'un ma ja'uk tz'in mak yu' ma jo'winikuk (sti)=

Why wasn't it then, perhaps it wasn't one hundred or so.

$((\rightarrow$ it was only worth 100 pesos (disputing P's claim in line 235). ))

$=$ mak bit'il ta' ya stoytik yu' mak ja' te sle bi xan ae

How is it that they overstate (the price of the belt) because perhaps it's that she $(\mathrm{P})$ is looking for something more (from me)!

$(\ldots \ldots \ldots \ldots \ldots)$

[

P: ya stak xa'leben (.)

You can look for (it - a belt) for me,

ya stak' xa'leben sjol teme jiche

you can look for a replacement for it for me if

that's how it is. ( $\rightarrow$ 'If you think that

was a cheap belt, get a better one!'))

D: 
$=$ ma ja' (tay tz'in men)

perhaps it's not (that)

[ ]

P:

manchuk a tz'in mak yu' ma toyoluk k'uxel tz'i $=244$ So what about that then, perhaps it's not that it was expensive then $((\rightarrow$ 'It was expensive!'))

D: = toyol nanix stukel a tz'i bi mak

Really expensive, (it is) itself then, perhaps eh?

$((\rightarrow$ sarcastic agreement: 'It was really cheap!'))

Now, as I develop in detail elsewhere (Brown 1990), not only in terms of how ironic expressions are used, but also in many other ways, the interactional conduct of a Tzeltal court case - a formal arena for face-toface confrontation with the aim of settling disputes between people - is the inverse of interactional conduct in 'ordinary conversation' in 'Tenejapan society. That is, ordinary conversational structures and interactional norms are systematically violated in a public display of indignation and anger. In this context, certain features - like irony - pervasive in women's speech in amicable conversation, features which are there used to convey positive affect, empathy, agreement, sympathetic understanding, are here used to convey the opposite: negative affect, hostility, contradiction.

In amicable interactions women's positively polite ironic phraseology assumes and stresses shared values and norms, mutual sympathy and understanding. In the courtroom confrontation this stance is evoked, but from a distance, ironically, in the sarcastic politeness of hostile pseudoagreement. Presumably the courtroom frame, the mutual knowledge of licence for inverted conventions in this special context, as well as all the additional information about hostility (conveyed by kinesics and eye contact, intonation and gesture) makes it not only possible but inescapable that the ironic utterances in this context must be interpreted as the opposite of what they would be interpreted as, were they to appear in a cooperative context. Certainly in the courtroom, the use of irony does not imply that the interactors know each other well, or share the same attitudes.

This suggests that in order to understand how even conventionalized ironic/rhetorical utterances are actually interpreted in speech, we need to look very closely at the uses of such forms of expression in different situations. One situation casts light on others, especially if one (like confrontation) is defined in opposition to the other (courteous interaction). The meaning-in-context of ironic expressions is clearly different in the two cases. 


\section{An ambiguous case}

It will be instructive, therefore, to look at one more interaction, where what is going on is much more indeterminate. A woman (T) had come visiting to request an injection from one of the women (A) in the household who is authorized to give injections. A wasn't home, but T talked to A's sister X. Throughout the ten-minute encounter, the kinesics, gaze avoidance, smirking, general body orientation, and displacement activity combined to indicate acute discomfort and embarrassment on T's part, and awkwardness mixed with surreptitious enjoyment by $\mathrm{X}$. The placement of ritual high pitch ${ }^{10}$ and the sequencing of utterances shows where the awkwardness is focused, and it is instructive to look at the treatment of ironically phrased utterances in this context. ${ }^{11}$ Example 12. Context: $T$ has been getting a series of injections from $A$, a local 'nurse'; she had come last night to get one but A had refused to give it. So $T$ came again today, understanding that there might be reluctance on A's part to give her an injection. It emerges during this encounter that there is reluctance, due to gossip that $\mathrm{A}$ heard $\mathrm{T}$ said about her $(\mathrm{A})$.

In this excerpt ' $T$ is trying again; $A$ isn't home but $T$ has been invited by $X$ to wait for $A$. After $T$ and $X$ chat about where $A$ is, when she'll be back, health, weather and work, $X$ mentions directly that $A$ is angry. (Underlined line numbers indicate ironic/rhetorical utterances.)

x: ay ja' chikan ya xlijkix sk'ajk'al ya'wil tz'ine mak

It's apparent that she has begun to get angry, you see, perhaps.

$\begin{array}{ll}\text { T: } & \text { eh yak ye in } \\ \text { eh, yes so it is }\end{array}$

[

x: $\underset{\text { Yes. }}{=}$ yak $=$

$\mathrm{T}:$ = ma sk'an a xjulonix tal ye tz'in $=$

She doesn't want to give me the injection.

$\mathrm{x}$ : = ej: lijkem laj sk'ajk'al

Oh, she's gotten angry, (someone) says

T: jai: bi laj yu'uni

What! Why (is she angry), does (someone) say?

x: baxa'wili

Who knows? ((Lit: Where do you see it? implies 'your guess is as good as mine'.))

T: yu' mati ay ya'yojben ka'yeje

Perhaps she's heard something I said.

$\mathrm{x}$ : ay niwanix yu'un ay (.) k'anix ta yu' ay a ka'ye

Perhaps that's it - I think I heard that that's it.

At this point, despite her disclaimer ('Who knows?') and hedges ('I think', 'perhaps') it is clear that $\mathrm{X}$ has definite information about what someone 
said T said about A; and T's belief that this is the case is made evident in her replies and direct question to $\mathrm{X}$ in line 134:

$\mathrm{T}:=\uparrow$ binti laj xon ek tz'in

So, what did (someone) say I said?

(0.5)

$\mathrm{x}: \uparrow$ ma xkil (.) ay nax

Who knows? ((Lit: I don't see)). It's just -

[

mach'a (.) mach'a xan ya'yej ek tz'in

Who - who said it then?

$\mathrm{x}$ : $\uparrow$ ma xkil me tz'in ma ba jojk'oyebe te banti ya'yoj a'yeje

Who knows, I didn't ask her where she heard the gossip (about what you said about her).

T: jai:

What?

x: ju'uj

No (I didn't ask her).

T: ah solel ay wa'y ta ba'ay wejtem bi ka'yej

$\mathrm{Ah}$, just look where my words have become available!

((i.e., 'just look how what I said got spread around!'))

$\mathrm{x}$ : ay niwan ay in

That's perhaps what happened.

$\mathrm{X}$ 's diplomatic denial of knowledge of the source of the gossip-mongering prompts T's defence in line 141 ('just look how my words have been spread around!') to which X's superficially agreeing reply ('That's perhaps what happened') could be interpreted either as sympathetic agreement or as sarcastic pseudo-agreement. She follows it up by quoting T's alleged talk about A:

T: mm: (1.0) mach'a me xkal

$\mathrm{Hm}$, who could it be (who told on me)?

((Lit: Who (is it) I say?)) $\mathrm{x}$ :

$$
\begin{aligned}
& \text { kaxel= } \\
& \text { 'Golly, }
\end{aligned}
$$

$=$ ma'yuk ba'ay bak'en ya xba sjulon mene me xat (.)

that one (A) certainly doesn't want to give me an injection,' if (that's what) you said,

mm bi'ora ay k'anbe spoxil mene bi'ora sjulon mene me xat,

$\mathrm{Mm}$, 'When is that one (A) going to get my medicine, when is she going to inject me?' if you said.

$\uparrow$ bi laj bal ut'il

What's the use of it? ( $\rightarrow$ No use, A implicated, in this reported conversation with $\mathrm{X}$.$) )$

Here the direct quotes put the rhetorical question in the mouth of the quoted speaker (A), and $\mathrm{X}$ thus remains uncommitted as to whether she shares the attitude indicated (i.e., 'why bother to provide injections for this woman who bad-mouths me to others?'). T responds with the 
standard indication of non-hearing or non-comprehension, jai?, prompting $\mathrm{X}$ to expand on her claim:

x: xi a ka'y ja' ya yali (.) peru ma ba la jojk'o mach'a yaloj

I heard her say, so they say. But I didn't ask who said it.

$\mathrm{T}$ : mach'a yaloj $\mathrm{xkal}=$

Who reported that, I wonder? ( $\left(\rightarrow{ }^{\prime}\right.$ No one knows.' $\left.)\right)$

$\mathrm{x}$ : ju'u

No. ((Replies to implicature: 'No, no one knows.'))

Having agreed (for current purposes, at least), that they don't know who the gossip-monger is, $\mathrm{T}$ goes on to deny her alleged words:

T: ma'yuk to ba'ay ya xlok'on ta (.) a'yej a ka'y

I didn't go around saying (those things) at all, I say!

$x$ : ma'yuk

(You) didn't at all.

T: ma'yuk, ma'yuk ba xlok'on ta julbal

Not at all, not at all did I go out visiting ( $\rightarrow$ and gossiping)).

$\mathrm{x}$ : ay (0.5) ay niwan ja' jich ya xlijk yala k'ajk'al yu'un ek tz'in

It's, it's perhaps that that made her (A) get a bit angry then.

T: ah: mak bi yu'uni lijk sk'ajk'al a ka'y tz'in

Oh, why did she get angry then?

$((\rightarrow$ 'How unfair, how could she?!'))

$\mathrm{x}$ : bi yu'uni ya xlijk a'k'ajk'ali uta (tz'in)

'Why are you angry?' you should say to her (then).

T: ya kalbe i mak

Perhaps I'll say that to her.

They go on, shifting around the issue, $T$ continuing to deny she said anything and to wonder who could have gossiped about her, $\mathrm{X}$ continuing to prick her, indirectly. The topic winds down, as follows:

x: ya'wa'y (.) ya'k'anbe nix xan wokol (.)

You see, you just ask her again to take the trouble (to inject you).

T: yaka'y

I see.

$\mathrm{x}$ : slajinbet ine yip xix jich a tz'i $=$

She'll just finish you up (i.e., finish the series of injections).

T: $=$ yip $=$ just (finish)

$x:=b i j a$ ' to tz'in te ay ba'ay (.) yax-k'ejel xa'wakix a'ba ta julel yu'un a $t z$ 'ine

So how is it then, that there is somewhere else you can go to get injected then $((\rightarrow$ 'Nowhere else can you go to get injections.' $))$

T:

ja' to $x a n=$

There still is somewhere else

$((\rightarrow$ 'There sure isn't!'))

$=$ sok banti ya jta me ineksione $=$

and where will I find an injection? $((\rightarrow$ Nowhere!))

$=$ mak yu' ay jich (.) jtaoj ta jleel ek tz'in $=$ 
Perhaps that's how it is, I've found (another injection-giver) then (( $\rightarrow$ 'I haven't.'))

= te manchuk ja'uk tz'in te (wa'y) bi jpasoj ch'e

so what if that's how it were then, (you see) what I'd have done (if there were an alternative to $A$ as injection-giver).

$((\rightarrow$ 'I couldn't do anything if A refused, as there's no alternative to her services.'))

x: ja' ya'wa'y

That's so, you see

T: ja'

It is.

x: ja'

It is.

$\mathrm{T}$ : ja'

It is.

$x$ : jich ya'wa'y tal (.) ya niwanix slajinbet $t z$ 'in,

So you'll see, she'll perhaps finish you then,

yu' bal kejchel ya xk'ot a'wu'un

because is it that you'll be finished (with your series of injections) otherwise?

( $(\rightarrow$ 'Of course not, there's no one else to do it.'))

$\mathrm{T}$ : baxa'wil

Where, you see?

$((\rightarrow$ Nowhere else (can I get injections!').))

(The embarrassment more or less resolved, they go on talking of other things.)

In this example, then, the shared common ground on which ironic expression normally relies is missing $-\mathrm{X}$ doesn't believe $T$ didn't do this gossiping about A. X's scepticism is made clear despite her denials (e.g. lines 128,138 ) and hedges (line 130), and her agreements with T's denials (line 154). For example, the contradiction between line 154, where $\mathrm{X}$ (superficially) agrees with T's denial of culpability to the accusation of gossiping, and line 156, where X says that it's T's gossiping that made A get angry, clearly indicates her actual belief.

Their relationship in this context is asymmetric, as $T$ is a suppliant for A's services and $X$ is a mediator between the allegedly angry non-present $A$ and the suppliant $T$. In this context, $T$ 's rhetorical questions and ironic utterances are essentially aimed at eliciting $X$ 's sympathetic understanding for her plight (needing A's injection-services, A reluctant to provide them) (e.g. lines 125, 157, and 238-40). X's are more multi-functional, for example denying knowledge and responsibility with the conventionalized Tzeltal verbal equivalent to a hands-in-air gesture of hopeless fatalism $(b a$ xa'wili or ma $x$ kil ('who knows', lines $128,136,138$ ), followed by a patent social lie ('I didn't ask her where she heard the gossip', line 138). Others are potentially barbed, carrying a dual message as in lines 237 ('Is there somewhere else you can go to get injections?' and 248 ('Will you finish your injections otherwise?'), which can simultaneously be read as taunt- 
ing or as sympathetic understanding for T's plight. And since T, in her response to X's potentially dual message, in line 238 takes up the second of those meanings, responding with an ironic agreement to the ironic implicature in X's line 237 (saying, in effect, 'I agree, there certainly isn't anywhere else I can go to get injected, oh poor me.'), she humbles herself by throwing herself in effect on X's (and thereby A's) mercy. As she solicits sympathy with piled-up ironies (lines 238-40), and accepts X's rubbing it in with agreements (lines 242,244 ) and re-phrasings of 'T's dilemma (line 248), the uncomfortable ambiguity vanishes ( $T$ is humbled, $X$ triumphant) and they can carry on conversing amicably.

This example shows that topic-summing-up with ironically phrased utterances does not necessarily display real common ground in the sense of shared attitudes. The agreement that there is nowhere else to go to finish her injections does not necessarily carry with it sincere humility on T's part, nor sincere sympathy on X's; the surface agreement simply provides a negotiated end to the topic.

\section{Conclusion}

The use of ironic expressions in Tzeltal is an elaborate and complex phenomenon, but I have used it to make a very simple point. One cannot mechanistically apply the Brown and Levinson model of politeness strategies to discourse data; particular linguistic realizations are not ever intrinsically positively or negatively polite, regardless of context. Politeness inheres not in forms, but in the attribution of polite intentions, and linguistic forms are only part of the evidence interlocutors use to assess utterances and infer polite intentions. So however many pleases, thank yous, bows and scrapes you may make, the polite attitude supposedly conveyed by them can be undermined, inverted, or cancelled by their interaction with other elements in the context, and interactors can't just sit back and let conventionalized expressions do their interpretive job for them. Rather, they must constantly work at inferring each other's intentions, including whether or not politeness is intended. This is especially obvious with irony, where they have to infer whether an utterance is ironically intended, whether it is ironic irony, who, if anyone, is the intended target or victim (obviously crucial to an interpretation of its politeness value), and who is the intended audience (in the court case, for example, the judge's role as arbitrator is crucial to the interpretation of the litigants' confrontational performance).

Successful irony thus relies completely on interlocutors' (and audiences') ability to decode mutual knowledge assumptions about what each thinks the other thinks must be true. The Tzeltal examples demonstrate that the reflexive reasoning involved must be at least four levels 
Table 7.1. Levels of reflexive reasoning

\begin{tabular}{ll}
\hline Sincere assertion & I assert $P$ \\
& I believe that you believe I believe $P$ is true \\
I hope therefore to get you to believe $P$ is true \\
True deception & I assert not- $P$, though I believe $P$ is true \\
I hope you believe I believe $P$ is not-true \\
I therefore hope you'll believe $P$ is not-true \\
Pseudo deception \\
(social lies) \\
I assert $P$, though I believe not-P is true \\
I believe you believe I believe $P$ is not-true \\
I believe you know (and believe I know) the customs concerning \\
constraints on revealing certain kinds of information \\
I therefore don't expect you to believe $P$, but to desist from \\
pressing for this kind of information \\
I 'mention' $P$, hoping to evoke $Q$ (which is systematically related to \\
Irony \\
I want you not to think I believe that $P$ is the case \\
I believe you believe I believe that not-P is the case, and \\
I believe you believe I believe you believe that not-P is the case \\
I therefore hope you will respond to $Q$ \\
I 'mention' $P$, in the frame of non-serious joking \\
I believe $P$ is true, and I believe you believe $P$ is true \\
I believe you know this is non-serious talk, and therefore hope you \\
will within this joking frame take not- $P$ to be true for current \\
purposes
\end{tabular}

deep. An informal Gricean account of these levels might go along the lines presented in Table 7.1.

There are of course many clues, in addition to Gricean flouts of sincerity, to prod the inferential process in a particular direction, restricting the range of possible meanings a speaker is, in the context, likely to be taken as intending, or hinting at his or her actual intentions. These include 'background knowledge' of the interlocutors' previous interactional history, their social roles and relationship, the nature of the speech event, and the immediately preceding discourse, insofar as it provides a record for current purposes of their respective beliefs. The characteristics of the ironically phrased utterance itself may also provide clues: non-verbal affective cues in the kinesics, facial expressions, and gestures accompanying the utterance; intonational and paralinguistic cues (timing, voice quality, stress). ${ }^{12}$ In Tzeltal, especially important is the special set of emphatic and hedging particles which combined together force an ironic reading: an utterance along the lines of 'Perhaps it might be the case that $P$, to be sure!' can only be read as emphatically asserting not-P.

Furthermore, in Tzeltal the fact that irony is a conventionalized form for expressing sympathetic understanding affects the interpretive process, providing an extra layer as it were of possible embedding in the form of joking or of sarcastic irony-as-pseudo-agreement. 
Nonetheless it is important that irony plays a role not only in welldefined interactions where a speaker's intent can in general be presumed to be either clearly sympathetic (as in positively polite 'grooming') or clearly hostile (as in confrontations). Irony in Tzeltal is exploitable as a resource for obscuring one's communicative intentions, muddying the waters so that interactors with potentially different goals can pursue them without flaunting their differences overtly. The indeterminacy of the relation between a speaker's expressed attitude and his or her real attitude may be put to the service of various devious interactional goals.

We might well ask: why in the world do Tenejapans bother to do all this? Why elaborate a form of discourse where you have to be constantly figuring out whether your interlocutor means what (s)he says, or the opposite, or the opposite of the opposite? Part of the answer might be that the very reliance of irony on mutually shared knowledge and values makes it a good test of whether in fact interlocutors do share knowledge and values, and thereby an excellent way of emphasizing and reinforcing claims to common ground. It is thereby an essential element in constructing the social relationship between the interlocutors, insofar as it succeeds in constructing the 'phatic communion' that inheres in demonstrations of mutual understanding. It is clear that in Tenejapa, for women at least, such interactions are an integral part of their social relations, they must have such conversations in order to consider themselves related to each other. That is perhaps the motivation behind positively polite uses of irony; then, given this resource, it is an obvious next step to its exploitation in order to sneer or insult.

I would suggest that there is a further reason why Tenejapan women, especially, make such elaborate verbal play with 'literally false' assertions, especially in relation to public opinion, and why they have elaborated their humour around the paradoxes which they pose. The ways in which women joke by claiming false things about themselves and each other precisely those false things which in others' mouths would humiliate and destroy them (about their sexual exploits and desires, their failures as fulfillers of female roles, etc.) - is a way of neutralizing the destructive power of such falsehoods, just as joking about illness and death ("Maybe I'll be permanently lame from this sore on my leg; maybe I'll die from it.') is a way of undermining the poignancy of fears about incapacity and death that both men and women have in this society. Men, not nearly so vulnerable to the effects of gossip about their sexual - and sex role misbehaviours, do not take the same lines in their solidarity-stressing joking. I think it is significant that men, to stress solidarity with each other, joke about what they do do, would do if they could, or have caught someone else doing; whereas women joke about doing what they wouldn't be caught dead doing and would be mortified and appalled if anyone seriously suggested that they would. 
It seems probable that irony is a typical communicative strategy for certain kinds of social groups. Tenejapa, for example, is a 'gossip society', a small-scale face-to-face society where people are obsessed with what everyone is saying about others, and especially about themselves. ${ }^{13}$ This may make it a good candidate for the sociolinguistic elaboration of ironic expression. I would also suggest that irony is a common strategy for the underdog, for persons in subordinate or vulnerable positions. Irony is a way of tacitly complaining about one's lot in life - of some of the consequences of one's underdog position - without actually upsetting the status quo. The complaint is off record (very much so in these ironic joking scenarios where interactors set up public opinion against themselves) and it essentially affirms the right of public opinion to maintain such an eagle eye on their behaviour. Indians have for 500 years been the underdogs in Mexican society, and women have been the underdogs within the Tenejapan community; this objective status contrasts with their strong sense of ethnic identity and community pride. As a technique for making play with the ambiguities of this contrast, irony seems ideally designed.

Finally, to return to the AIP model - Tzeltal irony provides a prime example of one way in which humans' highly developed intellectual machinery for inferring alter's intentions is put to the service of social relationships. Language allows us to make propositions, with which we can plan, discuss the future and non-present events, propositions which can be used non-seriously to joke, which can lie, or pretend (play-lie), and which can evoke mental models which are held up for affective comment (e.g., ridicule or contempt). The process of doing this successfully $i s$ to a large extent the social relationship of solidarity in Tenejapa, and this institutionalized socio-cultural strategy, in the form of a particular 'way of putting things', puts a characteristic stamp on Tenejapan social interaction.

\section{Acknowledgements}

This chapter amalgamates some points described in more detail in Brown (1990) with my analyses of Tzeltal irony first presented at seminars in Australia (Australian National University, 1982) and London (Sociolinguistics Symposium, 1989), as well as in Brown (1979: ch. 4). I am grateful to Stephen Levinson, Esther Goody, and John Haviland, and to the other participants in these seminars and the Workshop On the Implications of a Social Origin of Human Intelligence, for their helpful comments.

\section{Notes}

1 This fieldwork - over the past twenty years - has focused primarily on social interaction in Tenejapa, and a large corpus of tape-recorded and/or filmed 
naturally occurring Tzeltal interaction has been built up, from which the data analysed here has been drawn. Tenejapa is a municipio in the Chiapas highlands, in a heavily populated rural area where there are many other communities of Tzeltal or Tzotzil speakers, each of which maintains a strong ethnic identity distinguishing it from the others and from the dominant Ladino (Mexican national) culture.

2 That is, where $\mathbf{P}$ can be expressed by any well-formed Tzeltal sentence, the position of the subjunctive suffix $-u k$ (which conveys possibility-hedging) mutatis mutandis. The notion of 'opposite' is not quite accurate for the case, as Stephen Levinson has pointed out. Tzeltal irony is not just a matter of asserting $\mathbf{P}$ and conveying not- $\mathrm{P}$, or vice versa, but rather something like the following: an assertion is made to the effect that one end of a scale is (possibly) the case, and in context this implicates the emphatic assertion that the other end of the scale is the case. Irony thus forces descriptions to polarized ends of a continuum of evaluation on some dimension (good/bad, desirable/undesirable, likely/unlikely, and so forth). I use 'opposite' as a shorthand for this flip between conveying the ends of an evaluative continuum.

3 For some discussions of irony in relation to the Gricean maxims, and in discourse contexts, see the references cited in Brown and Levinson (1987: 28).

4 Despite its omni-presence, ironical phrasing of utterances is not to my knowledge an 'emic' Tzeltal category. While Tenejapans explicitly distinguish two basic categories of speech, $p o k o-k$ ' $o p$ (traditional, ritual speech styles - in Stross's (1974) characterization 'elegant, stylized, serious, nonmalicious speech') vs. $a c h ' k$ 'op, ('recent speech' including all forms of nonserious speech), and while they have lexical items denoting particular kinds of non-serious speech (e.g., lotil, 'lies'; ixta-k'op, 'joking'; lo'il k'op, 'carnivalstyle joking'; tajimal $k$ 'op, 'verbal games', labanel, 'mockery'), I don't know of any label specifically designating conventionalized Tzeltal irony.

5 In Brown and Levinson (1987) we make the following distinctions: joking, which as a positive politeness strategy stresses in-group relations and common ground, and can include non-serious insults; mockery, which when of someone other than the addressee can stress in-group solidarity; teasing, which can be joking or mockery even with the addressee as target, but playful; and irony, which is at root an off-record strategy but if on record in context can be positively polite solidarity stressing.

$6 \mathrm{~S}$ stands for 'speaker' $\mathrm{H}$ for 'addressee'. The Tzeltal practical orthography has the following conventions (where they differ from the International Phonetic Alphabet): j represents $/ \mathrm{h} /$, ch represents $/ \check{\mathrm{c}} /$, $\mathrm{x}$ represents $/ \mathrm{J} /$, tz represents $/ \mathrm{ts} /$ and ' represents either glottalization of the preceding consonant or, following a vowel, a glottal stop. Abbreviations for morpheme by morpheme glosses used in the text are as follows: ASP stands for neutral aspect, EMPH for emphatic particle, EXIST for the existential predicate, ICP incompletive aspect, NEG negative particle, $Q$ question particle, SUBJ subjunctive.

7 Note that in line 6 of this example the trigger for irony is not a patent falsehood but a patent truth, which within the non-literal joking frame must then be reinterpreted. The levels of inference required may be diagrammed as follows: 
lit: Because perhaps an Indian will marry you, you know. c.i.1: Of course no Indian will marry you; you'1l marry a Ladino. But: Ha ha, we both know you'll certainly never marry a Ladino. Therefore c.i.2: You're joking; of course you'll marry an Indian!

8 Tenejapans distinguish 'real' lies (lotil-lies intended not to be seen through) from such joking lies, which are intended to reinforce solidarity. Akin to 'real' lies, perhaps, are those social lies which are non-joking but, though intended to conceal some fact, are so obviously false that there is no real deception. For example, in response to a 'nosy' question that one does not wish to answer (e.g., 'How much do you earn at that work?') a patently false answer is customary (e.g., 'I don't know, I can't count' or 'Two pesos per month'); this implies that the speaker has no intention of answering such uninvited questions. The effect of real lies, then is interactionally distancing, in contrast to the joking lies (or elaboration of non-truths) which reinforce mutual knowledge, mutual values, and friendship.

9 For conventions used in the transcription of this and the following example, see the 'Conventions used in transcripts' on $p . x$.

10 Very high or even falsetto pitch is used in Tzeltal to convey deference in ritual speech, greeting and farewell exchanges, and wherever formality is being emphasized. It tends to characterize the beginnings and endings of encounters in general, and often marks socially sensitive or potentially threatening utterances, as well as fatalistic resignation. It is marked in the transcription by an $\uparrow$ preceding the utterance.

11 This interaction took place in 1980 and was filmed by S. Levinson and myself. The soundtrack was transcribed with the assistance of one of the participants, $\mathrm{X}$ herself.

12 In his analysis of 'sarcasm as theater', Haiman (1990) has observed that a number of these cues appear to be cross-linguistically applicable. He mentions three kinds (1990: 181): 'a. formal indices of direct quotation or repetition ...; b. incongruity between segmental and suprasegmental texts (incongruous suprasegmentals include the phonetic reflexes of sneers and laughter, deadpan monotone, caricatured exaggeration of the appropriate melody, and stylized or singsong intonation); c. hyper-formality (including both high register and the substitution of linguistic signs [like "ha, ha"] for paralinguistic symptoms [genuine laughter]).'

These 'stage separators' or mechanisms for indicating that what is acted out behind them is 'not serious' are not generally involved in routine Tzeltal ironies, though they (especially those under ' $b$ ') do mark as 'on stage' the joking sequences illustrated by example 9 . Tzeltal speakers do not seem to find it necessary to heavily mark their non-straight utterances as non-straight; the inferential trigger is more likely to be simply a conflict between the expressed proposition and mutually assumed knowledge.

13 See for example Haviland's (1977) description of the neighbouring Tzotzil community of Zinacantan. 